\title{
Identification of novel candidate target genes in amplicons of Glioblastoma multiforme tumors detected by expression and CGH microarray profiling
}

\author{
Yolanda Ruano ${ }^{1}$, Manuela Mollejo ${ }^{2}$, Teresa Ribalta ${ }^{3}$, Concepción Fiaño ${ }^{4}$, \\ Francisca I Camacho ${ }^{2}$, Elena Gómez ${ }^{5}$, Angel Rodríguez de Lope ${ }^{6}$, Jose- \\ Luis Hernández-Moneo ${ }^{6}$, Pedro Martínez ${ }^{1}$ and Bárbara Meléndez*1
}

Address: ${ }^{1}$ Genetics Department, Hospital Virgen de la Salud, Avda. Barber 30, 45004-Toledo, Spain, ${ }^{2}$ Department of Pathology, Hospital Virgen de la Salud, Avda. Barber 30, 45004-Toledo, Spain, ${ }^{3}$ Department of Pathology, Hospital Clinic, Barcelona, C/Villarroel, 170, 08036-Barcelona, Spain, ${ }^{4}$ Department of Pathology, Complejo Hospitalario Xeral-Cies, C/Pizarro, 22, 36204-Vigo, Spain, ${ }^{5}$ Banco de Tumores, Spanish National Cancer Centre (CNIO), c/Melchor Fernéndez Almagro 6, 28029-Madrid, Spain and ${ }^{6}$ Neurosurgery, Hospital Virgen de la Salud, Avda. Barber 30 , 45004-Toledo, Spain

Email: Yolanda Ruano - yruano@sescam.jccm.es; Manuela Mollejo - mmollejov@sescam.jccm.es; Teresa Ribalta - TRIBALTA@clinic.ub.es; Concepción Fiaño - concepcion.fiano.valverde@sergas.es; Francisca I Camacho - fcamachoc@sescam.jccm.es;

Elena Gómez - megomez@cnio.es; Angel Rodríguez de Lope - angelr@sescam.jccm.es; Jose-Luis Hernández-Moneo - jlhernandez@sescam.org Pedro Martínez - pmartinez@sescam.jccm.es; Bárbara Meléndez* - bmelendez@sescam.jccm.es

* Corresponding author

Published: 26 September 2006

Molecular Cancer 2006, 5:39 doi:10.1186/1476-4598-5-39
Received: 08 September 2006

Accepted: 26 September 2006

This article is available from: http://www.molecular-cancer.com/content/5/I/39

(C) 2006 Ruano et al; licensee BioMed Central Ltd.

This is an Open Access article distributed under the terms of the Creative Commons Attribution License (http://creativecommons.org/licenses/by/2.0), which permits unrestricted use, distribution, and reproduction in any medium, provided the original work is properly cited.

\begin{abstract}
Background: Conventional cytogenetic and comparative genomic hybridization (CGH) studies in brain malignancies have shown that glioblastoma multiforme (GBM) is characterized by complex structural and numerical alterations. However, the limited resolution of these techniques has precluded the precise identification of detailed specific gene copy number alterations.

Results: We performed a genome-wide survey of gene copy number changes in 20 primary GBMs by CGH on cDNA microarrays. A novel amplicon at 4p I5, and previously uncharacterized amplicons at 13q32-34 and Iq32 were detected and are analyzed here. These amplicons contained amplified genes not previously reported. Other amplified regions containg wellknown oncogenes in GBMs were also detected at 7p/2 (EGFR), 7q2। (CDK6), 4q।2 (PDGFRA), and I2qI3-I5 (MDM2 and CDK4). In order to identify the putative target genes of the amplifications, and to determine the changes in gene expression levels associated with copy number change events, we carried out parallel gene expression profiling analyses using the same cDNA microarrays. We detected overexpression of the novel amplified genes SLA/LP and STIM2 (4PI5), and TNFSFI3B and COL4A2 (I3q32-34). Some of the candidate target genes of amplification (EGFR, CDK6, MDM2, CDK4, and TNFSFI3B) were tested in an independent set of II I primary GBMs by using FISH and immunohistological assays. The novel candidate I3q-amplification target TNFSF I $3 B$ was amplified in $8 \%$ of the tumors, and showed protein expression in $20 \%$ of the GBMs.

Conclusion: This high-resolution analysis allowed us to propose novel candidate target genes such as STIM2 at 4pI5, and TNFSFI3B or COL4A2 at 13q32-34 that could potentially contribute to the pathogenesis of these tumors and which would require futher investigations. We showed that overexpression of the amplified genes could be attributable to gene dosage and speculate that deregulation of those genes could be important in the development and progression of GBM. Our findings highlight the important influence in GBM of signaling pathways such as the PI3K/AKT, consistent with the invasive features of this tumor.
\end{abstract}




\section{Background}

Glioblastoma multiforme (GBM) is the commonest and most malignant of the primary central nervous system tumors in the human adult. Mean survival of GBM patients treated with the current standard therapy is approximately one year [1].

Glioblastomas, like other solid tumors, are characterized by changes in the expression of oncogenes and tumor suppressor genes, often as a consequence of numerical chromosomal abnormalities (genomic amplifications, gains, and losses) that occur during the tumoral process. Conventional and molecular cytogenetic techniques, such as comparative genomic hybridization (CGH), have led to the identification of recurrent genomic copy number changes that play an important role in the malignancy of GBM. Aberrations that occur with high frequency include gains of chromosomes 7, 19, and 20, and losses of chromosomes $6 \mathrm{q}, 9 \mathrm{p}, 10,13 \mathrm{q}$, and $14 \mathrm{q}[2,3]$. Nevertheless, the low resolution of these techniques, which is restricted to the chromosome level, together with the large number of genes located within these regions, makes difficult the identification of candidate genes.

High-level DNA copy number changes in tumors are restricted to chromosome regions that show more than 5to 10 -fold copy number increases (regions of amplification, or amplicons). Some of these amplicons contain well-known oncogenes that are also overexpressed. While this is the case for oncogenes associated with the development of GBM, such as Epidermal Growth Factor Receptor (EGFR) (7p12), Cyclin-Dependent Kinase 4 (CDK4) (12q14), and the human homolog of the Mouse Double Minute 2 (MDM2) (12q15) [2-4], other regions of amplification and/or other relevant genes located within these or other regions remain unknown or incompletely described.

New high-throughput genomic technologies, such as cDNA microarray CGH [5], use conventional cDNA microarrays that are normally used in expression profiling, to examine genomic copy number imbalances. In this way, thousands of genes can be reviewed in a high-resolution analysis to define amplicons and identify candidate genes showing recurrent genomic copy number changes. Parallel expression profiling experiments then allows the identification of relevant target genes whose aberrant expression could suggest its involvement in the pathogenesis of the tumors [6-10].

The objective of our study was to define at high resolution regions of amplification in GBMs, and through integration of copy number and gene expression data, to identify possible candidate target genes that could give insights into the pathology of GBM. In addition, we also aimed to analyze in detail the gene copy number changes associated with these tumors, since this is not feasible using classic chromosomal CGH.

For that purpose, we surveyed for changes in DNA copy number and expression levels throughout the genomes of 20 primary GBMs by using cDNA microarray CGH and expression profiling experiments. The most significant alterations found were validated in additional series of primary GBMs using locus-specific fluorescence in situ hybridization (FISH), and immunohistochemical analyses.

\section{Methods}

\section{Patients and tissue samples}

The genomic-profiling study involved 20 cases of primary GBMs. Expression profiling experiments were carried out in 17 of the GBMs for which RNA material was available. Thirteen of the patients were males and 7 were females with a mean age of 61 years (range, 39 to 81 years). The clinical information of the patients is summarized in Table 1.

To validate our results, 111 primary GBMs were arrayed in tissue microarrays (TMAs) and subjected to immunohistochemical and FISH analyses. Samples were collected from Virgen de la Salud Hospital (Toledo, Spain), Clinic Hospital (Barcelona, Spain) and Xeral-Cies Hospital (Vigo, Spain). All samples were reviewed by means of tissue sections stained with hematoxylin and eosin (H\&E) to verify tumor viability and confirm the diagnosis according to the WHO guidelines by M.M., T.R., C.F., and F.-I.C.

\section{CDNA microarray CGH and expression profiling}

The cDNA microarrays used in this study (Oncochip v2.0) were purchased from Centro Nacional de Investigaciones Oncológicas [11]. These microarrays contained 27,454 cDNA clones, including 9,900 known genes and uncharacterized ESTs related to tumorigenesis.

High molecular weight genomic DNA from tumors and normal human lymphocytes (used as reference DNA) were extracted following standard phenol/chloroform purification protocols. CGH experiments on cDNA microarrays were performed as described $[5,10,12]$. Briefly, 20 $\mu \mathrm{g}$ of genomic tumoral and reference DNAs were digested for 14-18 hours with AluI and RsaI (Life Technologies, Inc., Rockville, MD) and purified by phenol-chloroform extraction. Six $\mu \mathrm{g}$ of purified digested tumor DNA and reference DNA were labeled with Cy5-dUTP and Cy3-dUTP (Amersham Biosciences, Piscataway, NJ), respectively, using the Bioprime Labeling Kit (Life Technologies, Inc.). Labeled tumor and sex-matched reference DNA were cohybridized at $58^{\circ} \mathrm{C}$ for $14-16$ hours. Post-hybridization washes were carried out in $2 \times \mathrm{S} \mathrm{SC} / 0.03 \%$ SDS at hybridi- 
Table I: Clinical and molecular data of the patients.

\begin{tabular}{|c|c|c|c|c|c|c|c|c|c|c|c|c|c|}
\hline Case & Sex & Age & Site & OS & Status & $7 p$ EGFR & $I q$ & $4 p / 4 q$ & $7 q$ & I2q CDK4 & I2q MDM2 & $13 q$ & $-10 q$ \\
\hline C29 & $M$ & 39 & $\mathrm{~T}$ & 46 & $A$ & $\mathbf{A}$ & & & & & & & \\
\hline C34 & $\mathrm{F}$ & 81 & P-O & 4 & $A$ & A & & & & & & & $\mathbf{L}$ \\
\hline C35 & $M$ & 51 & $\mathrm{~T}$ & 3 & $\mathrm{D}$ & $\mathbf{A}$ & & & & & & & $\mathbf{L}$ \\
\hline C35b & $\mathrm{F}$ & 66 & $P$ & I & $A$ & $\mathbf{A}$ & $\mathbf{A}$ & & & & & & $\mathbf{L}$ \\
\hline C36 & $\mathrm{F}$ & 55 & T-P & 18 & $A$ & $\mathbf{A}$ & & & & & & & $\mathbf{L}$ \\
\hline$C 38 b$ & $\mathrm{~F}$ & 45 & T-P & 2 & A & $\mathbf{A}$ & & & & & & & $\mathbf{L}$ \\
\hline C42 & $M$ & 70 & T-P-TA & 2 & $\mathrm{D}$ & $\mathbf{A}$ & & & & & & & \\
\hline C47 & $M$ & 60 & $\mathrm{~T}$ & 10 & $A$ & $\mathbf{A}$ & & & & & & & \\
\hline C33 & $\mathrm{F}$ & 61 & $\mathrm{~T}$ & 16 & $\mathrm{D}$ & $\mathbf{A}$ & & & $\mathbf{A}$ & & $\mathbf{A}$ & & $\mathbf{L}$ \\
\hline$C 26$ & $M$ & 52 & F-T-P & 3 & $\mathrm{D}$ & $\mathbf{A}$ & & & & $\mathbf{A}$ & & & $\mathbf{L}$ \\
\hline C36b & $M$ & 41 & $\mathrm{~T}$ & 10 & $A$ & & & & & $\mathbf{A}$ & $\mathbf{A}$ & & $\mathbf{L}$ \\
\hline C48 & $M$ & 74 & $\mathrm{~T}$ & 7 & $\mathrm{D}$ & & & & & $\mathbf{A}$ & & $\mathbf{A}$ & \\
\hline $\mathrm{C} 28$ & $\mathrm{~F}$ & 77 & $\mathrm{~T}$ & 4 & $\mathrm{D}$ & & & & & & & $\mathbf{A}$ & \\
\hline C39b & $M$ & 53 & $\mathrm{~F}$ & 0 & $D$ & & & $\mathbf{A}$ & & & & A & $\mathbf{L}$ \\
\hline C32 & $M$ & 60 & T-P & 8 & $D$ & & & & & & A & & \\
\hline C30 & $M$ & 79 & T-P & I & $\mathrm{D}$ & & & & & & & & \\
\hline C3I & $M$ & 79 & 0 & 6 & $D$ & & & & & & & & \\
\hline C37b & $M$ & 75 & $\mathrm{~T}$ & 0 & $D$ & & & & & & & & $\mathbf{L}$ \\
\hline C43 & $\mathrm{F}$ & 53 & P-O & 3 & $A$ & & & & & & & & \\
\hline C46 & $M$ & 59 & $\mathrm{~T}$ & 9 & $D$ & & & & & & & & \\
\hline
\end{tabular}

Clinical data: sex ( $M$ male, $F$ female), tumor site ( $T$ temporal, $P$ parietal, $O$ occipital, $F$ frontal and $T$ thalamus), overall survival (OS) in months, and status ( $D$ death, A Alive).

Molecular data: (A) amplification, (L) loss.

zation temperature, $1 \times$ SSC and $0.2 \times$ SSC at room temperature for 5 minutes each.

For expression profiling experiments total RNAs were extracted with Tri Reagent (Molecular Research Center, Cincinnati, $\mathrm{OH}$ ) and amplified using a T7-based method, as previously described (11). Five $\mu$ gr of total RNA were used to produce double-stranded cDNA (Superscript Choice System, Life technologies, Inc.) and amplification of mRNAs was performed using the Megascript T7 in vitro transcription kit (Ambion, Austin, TX). A pool of aRNAs obtained from the Universal Human RNA (Stratagene, La Jolla, CA) was used as a standard reference in all hybridizations. Test or reference amplified RNAs (aRNAs) were labeled with fluorescent Cy5 and Cy3, respectively, and hybridized at $42^{\circ} \mathrm{C}$ for 15 hours. Two control RNAs obtained from non-tumoral brain (one of them from Stratagene) were used for normalization purposes.

After hybridizations, slides were scanned using an Axon GenePix 4100A confocal scanner. Image analysis was performed using GenePix Pro 6.0 software (Axon Instruments Inc., Union City, CA). Cy5/Cy3 fluorescence ratios were normalized for each microarray using the print-tip loess method and background subtraction with the Diagnosis and Normalization Array Data (DNMAD) tool [13].

\section{Microarray data analysis}

Data were preprocessed using Gene Expression Preprocessing Analysis Suite (GEPAS) [14] [see Additional file 1].
Cut-off points for defining gains and losses of genetic material in the test hybridizations were established as reported before $[7,10]$. The mean $\log _{2}$-transformed ratios derived from the self versus self experiments of normal genomic DNA in control hybridizations allowed us to establish the cut-off points for defining gains and losses. A value of the mean ratio +/- two standard deviations showed a normal range of variation corresponding to $\log _{2}$-transformed values of -0.42 to 0.42 . In order to ensure a fluorescence ratio of gain or loss, we considered gene gain to be when $\log _{2}$ ratios were $\geq 0.5$, and gene loss to be when $\log _{2}$ ratios were $\leq-0.5$. $\log _{2}$ fluorescent ratios $\geq$ 2 were considered to represent gene amplification.

\section{Fluorescence in situ hybridization and immunohistochemistry on TMAs}

TMAs were constructed using formalin-fixed paraffinembedded archival tissue blocks as reported [15]. Five non-tumoral controls ( 4 normal brain and one tonsil tissue samples) were included. H\&E-stained full sections from each donor block were used for morphological selections of the representative areas of each case.

FISH assays were performed as described previously [15] using gene-specific and control BAC clones selected from the EnsEMBL [16] and UCSC [17] databases (Table 2). Gene probes were labeled with SpectrumOrange-dUTP (red) and control probes with SpectrumGreen-dUTP (green) using the CGH Nick Translation Kit (Vysis). Hybridizations were done overnight at $37^{\circ} \mathrm{C}$ after depar- 
Table 2: Clones used for validation by FISH.

\begin{tabular}{lllll}
\hline Gene name & Gene-specific-BAC clones & Location & Control clones & Location \\
\hline EGFR & RPII-339FI3 & $7 p \mid 2$ & $\mathrm{p} 275 \alpha 7^{\mathrm{a}}$ & $7 \mathrm{cen}$ \\
CDK4 & RPII-57IM6 & $12 q|3-q| 4$ & RPII-467MI4 & $12 p \mid 3$ \\
MDM2 & RPII-6IIO2, RPII-450GI5 & $12 q \mid 5$ & RPII-467MI4 & $12 p \mid 3$ \\
ESTs on I3q & RPII-94PI7, RPII-406G20 & $13 q 32.2$ & & \\
& RPII-364F8, RPII-I5IA6, RPII-II3)24 & $13 q 33.3$ & & \\
\hline
\end{tabular}

\begin{abstract}
a plasmid probe located at the centromere (cen) of chromosome 7. The specificity and location of the probes were confirmed by FISH on normal metaphases before hybridization on the TMAs. When clones were available, and in order to increase the signal, two or three BAC clones around the test gene or EST were hybridized together. Control FISH experiments on normal interphase nuclei were performed beforehand in order to ensure a unique signal when two BAC clones were hybridized together. BAC clones on I3q were purchased from the BACPAC Resources Center (Children's Hospital Oakland Research Institute, CHORI). All other clones were generously provided by Dr. Rocchi.
\end{abstract}

affinization of $4-\mu \mathrm{m}$-thick sections of the TMAs, target retrieval by pressure-cooking with $1 \mathrm{mM}$ EDTA for 10 minutes, and pepsin digestion $\left(4 \mathrm{mg} / \mathrm{ml}\right.$ at $37^{\circ} \mathrm{C}$ for 30 minutes). After post-hybridization washes, tissue was counterstained with DAPI in antifade solution (Oncor, Gaithersburg, MD).

Fluorescence signals were scored (Y.R., B.M.) in accordance with previous reports [18]. In each sample, only welldefined nuclei were analyzed, and the numbers of singlecopy gene and control probe signals were scored. Tumors were considered as amplified when five or more unbalanced gene copies, or more than three times as many gene signals as control signals were found in more than $5 \%$ of tumor cells.

Immunophenotypic analysis was performed on deparaffinized TMA sections. For antigen retrieval, a heating step in a solution of $10 \mathrm{mM}$ sodium citrate buffer at pH:6 in a pressure cooker was included before incubation with antibodies. Tissues were immunohistochemically stained by the Labeled Streptavidin Biotin (LSAB) (DAKO, Glostrup, Denmark), or alkaline phosphatase-conjugated EnVision (DAKO) method, using the TechMate 500 (DAKO) automatic immunostaining device. The primary antibodies used were EGFR, MDM2 (Oncogene Research Products, Boston, MA) and TNFSF13B (BAFF or BlySS). Tumors were considered positive when membranous (EGFR), nuclear (MDM2), and membrane-bound or cytoplasmic (TNFSF13B) staining was observed in $\geq 5 \%$ of the tumor cells.

\section{Results}

\section{Impact of copy number alteration on gene expression}

The gene frequencies of gain and loss of genetic material found in the 20 primary GBMs were calculated, and plotted relative to the position along the chromosome (Figure 1). Chromosomes 7, 19, and 20 most frequently showed gains in copy number, while chromosomes 10 and 13 most frequently had losses (Table 3).
The global effect of copy number alterations on gene expression was evaluated in 17 of the primary tumors. Up to $33 \%$ of gained genes ( $>2.5$-fold change in copy number), or up to $56 \%$ with $>4$-fold, were overexpressed. Nevertheless, $8 \%$ of the genes with normal copy numbers were overexpressed (Figure 2A). Conversely, approximately $8 \%$ of the transcripts with high-level expression (>10-fold) showed amplification (Figure 2B).

\section{Gene amplifications in primary GBMs}

Amplicons were identified on chromosomes 1, 4, 7, 12, and 13 due to the presence of more than four contiguous amplified genes. EGFR (7p12) was the most commonly amplified gene (7p12), showing amplification by microarray CGH in $50 \%(10 / 20)$ of the GBMs (Table 1$)$.

The amplicon detected on chromosome 13 in tumor 39 (Figure 3A) contained contiguous amplified clones covering a region of about $2.5 \mathrm{Mb}$ at $13 \mathrm{q} 32-34$ that included TNFSF13B (a ligand of the tumor necrosis factor superfamily), and collagen type IV genes (COL4A1 and COL4A2). Among the amplified genes or ESTs, the most important fold-changes in expression levels were those of TNFSF13B, COL4A2 and FLJ10769. In addition, two other tumors had centromeric-amplified clones including ESTs AA706834, AA994053, and AI093016. However, these ESTs were not overexpressed.

To determine the frequency of $13 \mathrm{q}$ amplification in a larger series of tumors, we carried out FISH assays in an independent set of 111 GBM samples. We found 8,5\% of tumors (6/70) showing amplification (Figure 3B, 3C). In this same series, we examined the protein expression of TNFSF13B as one of the putative target genes of the $13 \mathrm{q}$ amplification. We detected TNFSF13B immunostaining positivity in $20,6 \%$ of the samples $(20 / 97)$. Half of the 13q-amplified tumors (3/6) showed TNFSF13B positive expression, and 7 out of $59(11,8 \%)$ non 13q-amplified tumors showed TNFSF13B positivity (Figure 3D). 


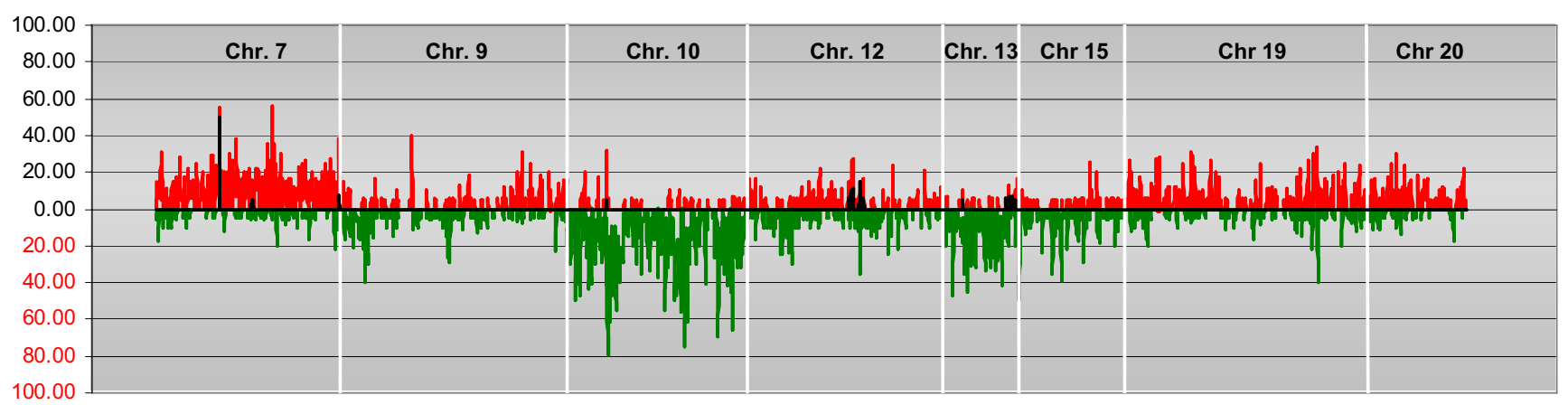

Figure I

Frequency of copy number change. (A) Frequency of gene amplification (black), gain (red), and loss (green) in the 20 GBMs relative to their map position in the EnsEMBL database (calculated as the number of GBMs showing amplified, gained, or lost genes vs. the number of tumors analyzed for each gene). The white vertical bars represent the separation between chromosomes. Only the most representative chromosomes are shown. Map positions for each cDNA clone were obtained from the EnsEMBL database using the IDconverter tool [45].

Amplicons were also detected on $1 \mathrm{q}, 4 \mathrm{p}, 4 \mathrm{q}, 7 \mathrm{q}$, and $12 \mathrm{q}$. Chromosome 4 had two separated regions of amplification (Figure 4A), one of about $6 \mathrm{Mb}$ at $4 \mathrm{p} 15$, and the other of approximately $2.2 \mathrm{Mb}$ at $4 \mathrm{q} 12$. The $4 \mathrm{p} 15$ amplicon is described here for the first time and contained several genes and ESTs not previously reported as being amplified in GBMs. The amplicon at 4q12 contained PDGFRA, whose amplification in GBMs is already well known. Among the amplified genes, SLA/LP, LOC389203, STIM2, SGCB, RASL11B, and PDGFRA seem to respond to gene dosage, presenting high fold-changes in expression levels (Figure 4A). Likewise, amplification of several contiguous clones on chromosome 1q32 included ATP2B4, KIAA0663, KISS1, PPP1R15B, PIK3C2B, and MDM4. Among them, ATP2B4, KIAA0663, PPP1R15B, PIK3C2B were overexpressed in the expression analyses (Figure $4 \mathrm{~B}$ ).

Chromosome 12 showed two regions of amplification at 12q13-15 (Table 4), one of about $180 \mathrm{~Kb}$ at $12 \mathrm{q} 13$ containing CDK4 (10\%, 2/19) and another one of about 700 Kb containing MDM2 (15\%, 3/20) at 12q14.3-q15. These results were validated by FISH analyses with specific probes containing CDK4 or MDM2 and immunohistochemical analyses for MDM2 onto paraffin sections of the samples in a set of 111 primary GBMs, allowing confirmation of the microarray results (Table 1 ). We found alterations (either amplification or overexpression) of MDM2 and CDK4 in $11 \%$ of the tumors for which data were available (11/98 and 7/66, respectively). Except for one tumor, the two regions were not amplified simultaneously. These results suggest that MDM2 and CDK4 may be independently amplified in most GBM tumors and confirm those of other authors [19]. Finally, amplification at $7 \mathrm{q}$ included PEX1, and CDK6 (7q21) as overexpressed putative amplification targets (Table 5).

\section{Discussion}

The overall impact of copy number on gene expression analyzed in GBMs reflects the importance of recurrent gene copy number changes in the development and progression of these brain tumors. Our results in GBMs extend previous studies in breast and prostate cancers $[10,20,21]$, and confirm that the effects of gene copy number on expression levels were more relevant for highlevel amplifications on a gene-by-gene analysis (56\% of highly-gained genes were overexpressed).

Gene amplification is regarded to reflect genetic instabilities in solid tumor cells [22]. It has been proposed that activation of proto-oncogenes by amplification plays an important role in the development of many human solid tumors. Therefore, detection of specific gene amplifications in tumor cells can lead to the identification of genes putatively involved in growth control and tumorigenesis.

While only a few candidate genes could be investigated at a time in previous studies $[4,23,24]$ we have used cDNA microarray technology to search the whole genome for gene copy number alterations in GBMs. Our results from the approximately 10,000 genes and ESTs related to the tumoral process that could be analyzed in this study, confirm the previous conclusion that EGFR is the principal oncogene amplified in GBMs. However, in this study several other chromosomal regions showing gene amplification have also been detected in GBMs at 1q, 4p, 4q, 7q, $12 \mathrm{q}$, and 13q. Amplification at 13q32-34 has been reported before from chromosomal CGH studies in malignant gliomas, cell lung carcinoma, head and neck squamous carcinoma, and systemic lymphomas [20,2529]. Here we have used microarray CGH to study this region at higher resolution (gene level) and have nar- 
Table 3: Frequent copy number and expression altered genes'.

\begin{tabular}{|c|c|c|c|c|}
\hline \multicolumn{5}{|c|}{ GAINED AND OVEREXPRESSED GENES } \\
\hline SYMBOL & GENE DESCRIPTION & $\%$ & MEDIAN & LOCATION \\
\hline ATP2B4 & ATPase, Ca++ transporting, plasma membrane 4 & 20.00 & 1.17 & $1 q 25-q 32$ \\
\hline LOCI53222 & Adult retina protein & 25.00 & 1.32 & 5 \\
\hline GBAS & Glioblastoma amplified sequence & 20.00 & 1.61 & $7 p 12$ \\
\hline GUSB & Glucuronidase, beta & 20.00 & 1.42 & $7 q 21.11$ \\
\hline RFC2 & Replication factor C (activator I) 2, 40kDa & 26.32 & 1.06 & $7 q 11.23$ \\
\hline MCM7 & MCM7 minichromosome maintenance deficient 7 (S. cerevisiae) & 35.29 & 1.02 & $7 q 21.3-q 22.1$ \\
\hline GIMAP6 & GTPase, IMAP family member 6 & 20.00 & 1.29 & \\
\hline LR8 & LR8 protein & 21.05 & 2.34 & $7 q 36.1$ \\
\hline APOE & Apolipoprotein E & 22.22 & 1.48 & $19 q 13.2$ \\
\hline EMP3 & Epithelial membrane protein 3 & 33.33 & 1.36 & $19 q 13.3$ \\
\hline FPRI & Formyl peptide receptor I & 25.00 & 1.94 & $19 q 13.4$ \\
\hline \multicolumn{5}{|c|}{ LOST AND UNDEREXPRESSED GENES } \\
\hline SYMBOL & GENE DESCRIPTION & $\%$ & MEDIAN & LOCATION \\
\hline CYPIBI & Cytochrome P450, family I, subfamily B, polypeptide I & 21.05 & -2.87 & $2 p 21$ \\
\hline TDE2 & Tumor differentially expressed 2 & 23.53 & -1.86 & $6 q 22.32$ \\
\hline OPTN & Optineurin & 41.18 & -1.86 & $10 p \mid 4$ \\
\hline DNAJCI 2 & DnaJ (Hsp40) homolog, subfamily C, member 12 & 25.00 & -1.16 & 10 \\
\hline SIRTI & Sirtuin (silent mating type information regulation 2 homolog) I & 27.27 & -1.27 & 10q22.1 \\
\hline PPP3CB & Protein phosphatase 3 (formerly 2B), catalytic subunit, beta isoform & 35.00 & -2.08 & $10 q 21-q 22$ \\
\hline GHITM & Growth hormone inducible transmembrane protein & 37.50 & -1.55 & $10 q 23.2$ \\
\hline CYP26AI & Cytochrome P450, family 26, subfamily A, polypeptide I & 21.05 & -1.08 & $10 q 23-q 24$ \\
\hline LGII & Leucine-rich, glioma inactivated I & 45.00 & -1.32 & $10 q 24$ \\
\hline SLK & STE20-like kinase (yeast) & 26.32 & -1.11 & 10q25.1 \\
\hline ADD3 & Adducin 3 (gamma) & 68.42 & -1.04 & $10 q 24.2-q 24.3$ \\
\hline MXII & MAX interactor I & 40.00 & -1.11 & $10 q 24-q 25$ \\
\hline ATRNLI & Attractin-like I & 30.77 & -1.65 & 10 \\
\hline KIAAI598 & KIAAI598 & 21.05 & -1.83 & $10 q 26.12$ \\
\hline NDFIP2 & Nedd4 family interacting protein 2 & 33.33 & -1.22 & $13 q 22.2$ \\
\hline MAP2K4 & Mitogen-activated protein kinase kinase 4 & 23.53 & -1.30 & $|7 p| 1.2$ \\
\hline DSG2 & Desmoglein 2 & 31.25 & -1.94 & $18 q 12.1$ \\
\hline TPTE & Transmembrane phosphatase with tensin homology & 22.22 & -1.67 & $2|p| \mid$ \\
\hline
\end{tabular}

IPercentage of tumors showing copy number and expression alterations (\%). Median of expression $\log _{2}$ ratios of copy number altered genes (median).

rowed down the region to $2.5 \mathrm{Mb}$, showing that this amplification could affect a small fraction of GBMs (8\%). Several known genes and uncharacterized ESTs are contained in the $13 \mathrm{q}$ amplicon. Among these, COL4A2 has also been found to be overexpressed in our study and in other microarray expression-profiling studies of GBM biopsies and GBM cell lines [30-32]. We speculate that this overexpression may have been caused by amplification of COL4A2, which may be a putative target of the amplicon. In agreement with this hypothesis, very recently, Tso and coworkers [33] have shown that COL4A2 is one of 15 highly expressed genes that is shared between primary and secondary GBMs. In addition, this gene was found to be involved in glioma progression and associated with vascular proliferation. However, immu- nohistochemical analyses revealed that collagen IV is mainly expressed in association with the tumor blood vessels and not from the tumor cells [32], suggesting that the COL4A2 overexpression detected in GBMs may not be as a result of gene amplification in tumoral cells. This may point out to TNFSF13B as a likely candidate for the target of amplification. Immunohistochemical analyses of 111 primary GBMs revealed that TNFSF13B could be affected in about $20 \%$ of the tumors. The TNFSF13B ligand (or BAFF) is a member of the TNF cytokine family that activates nuclear factor (NF)- $\kappa \mathrm{B}$, phosphatidylinositol-3 kinase (PI3K)/AKT, and mitogen-activated protein kinase (MAPK) pathways in myeloma multiple cells, and induce strong up-regulation of Mcl-1 and Bcl-2 antiapoptotic proteins [34].On another hand, the gene IRS2 (which 


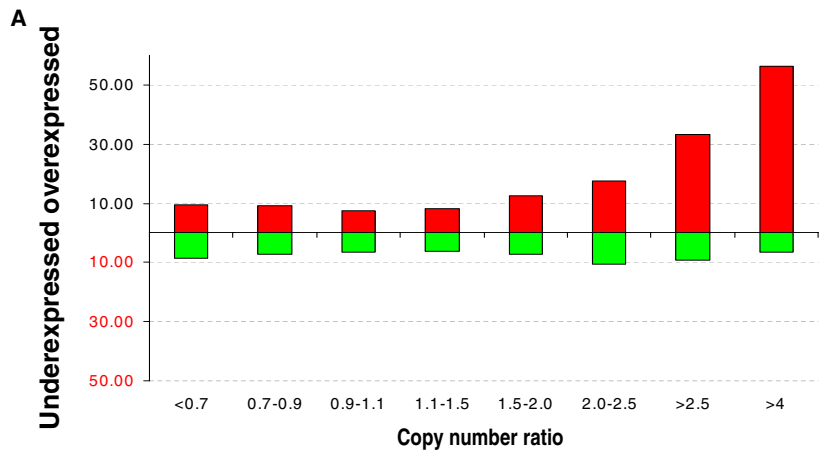

B

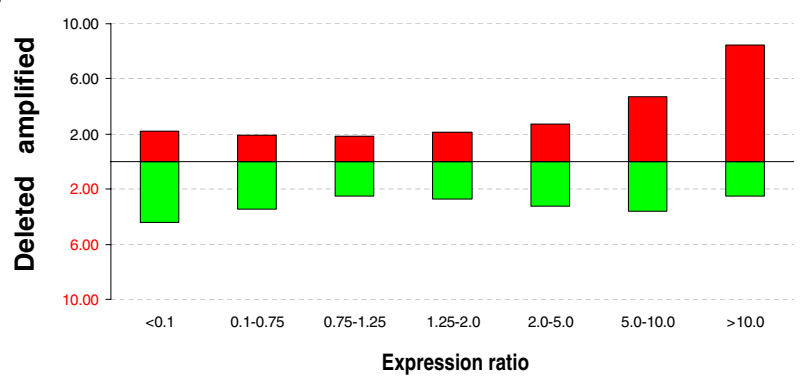

Figure 2

Impact of gene copy number on global gene expression levels. (A) Percentage of over- or underexpressed genes ( $Y$ axis) according to copy number ratios ( $X$ axis). (B) Percentage of amplified and deleted genes according to expression ratios.

codes a cytoplasmic adaptor protein that facilitates intracellular signal transduction) is also located within the amplified region close to COL4A2 and TNFSF13B. Although we have no data available for this gene, one study suggests that IRS2 is a novel but rare amplification target at 13q34 in GBMs [35]. Thus, we propose here that genes such as COL4A2 or TNFSF13B could be additional putative targets for the $13 \mathrm{q}$ amplicon, and therefore would warrant further detailed analyses in GBMs.

It is of particular note that two of the tumors showing this amplification in the telomeric region of chromosome 13 had loss of the rest of the chromosome (Figure 3A), as was also described by Weber and coworkers in the cases in which amplification was revealed by chromosomal CGH [36]. This finding is consistent with the finding that gene amplification may be accompanied by loss of genetic material in the proximity of the amplification site [37].

Chromosome 4 has two amplicons, located close together. One contains PDGFRA as the putative target of the amplicon, and the other contains SLA/LP, STIM2, and two ESTs. To our knowledge, this is the first report of amplification of SLA/LP and STIM2 genes, which are both overexpressed. However, further analyses are required to identify the amplification gene target(s) and to determine the relevance of this novel amplification in GBM. STIM2 codes for a transmembrane phosphoprotein whose structure is unrelated to that of any other known protein [38] and whose biological function has not been thoroughly studied. STIM1 is the other member of this family of proteins and it is thought to regulate cell growth control and function within a signaling cascade, although the precise pathway is not known [38].

There is controversy concerning the amplification on chromosome 1, as to whether 1q32 has two independent amplification targets or a single one affecting both MDM4 and CNTN2 genes [39-41]. We observed amplification covering a small region of about $800 \mathrm{~Kb}$ that excluded CNTN2. Thus, our results support the proposal of Riemenschneider and coworkers that MDM4 is the main amplification target gene at 1q32 [40]. However, other genes among those contained in the amplicon, such as PIK3C2B, which encodes a catalytic subunit of the PI3K, could be of importance in GBMs. This gene was also found amplified and overexpressed in GBMs by others $[32,41]$ and has a crucial role in the PI3K/AKT signaling pathway, which regulates a number of cellular processes such as cell growth and proliferation, apoptosis, migration and invasion, and angiogenesis [39]. Thus, our study excludes CNTN2 and shows that other interesting candidate genes together with MDM4 may be important gene targets for this $1 \mathrm{q} 32$ amplification.

Chromosome 7 was the most frequently gained chromosome in GBMs, as already known. Our results showed a large number of overexpressed gained-chromosome 7 genes which may suggest the importance of the complete gain of this chromosome in primary GBMs. Further studies, however, should be carried out to assess the importance of chromosome 7-candidate genes, other than $E G F R$, in the pathogenesis of GBM. Likewise, chromosome 10 was the most frequently lost chromosome in GBMs. The most frequently lost and underexpressed genes mapped at 10q and involved candidate genes in gliomas such as $A D D 3$, between others. Downregulation of $A D D 3$ expression was associated with increased migratory activity of human glioma cells in vitro [42], and decreased expression of $A D D 3$ has been described in astrocytomas [43]. Chromosome 19 also showed frequent gene gains, mainly located on 19q. One of the possible candidates located in this chromosome could be FPR 1 due to this gene is expressed in malignant glioma and appears to mediate motility, growth, and angiogenesis of GBM [44].

\section{Conclusion}

In summary, our results show that the cDNA microarray CGH technique in parallel with expression profiling allows the comprehensive, rapid and reliable analysis of 

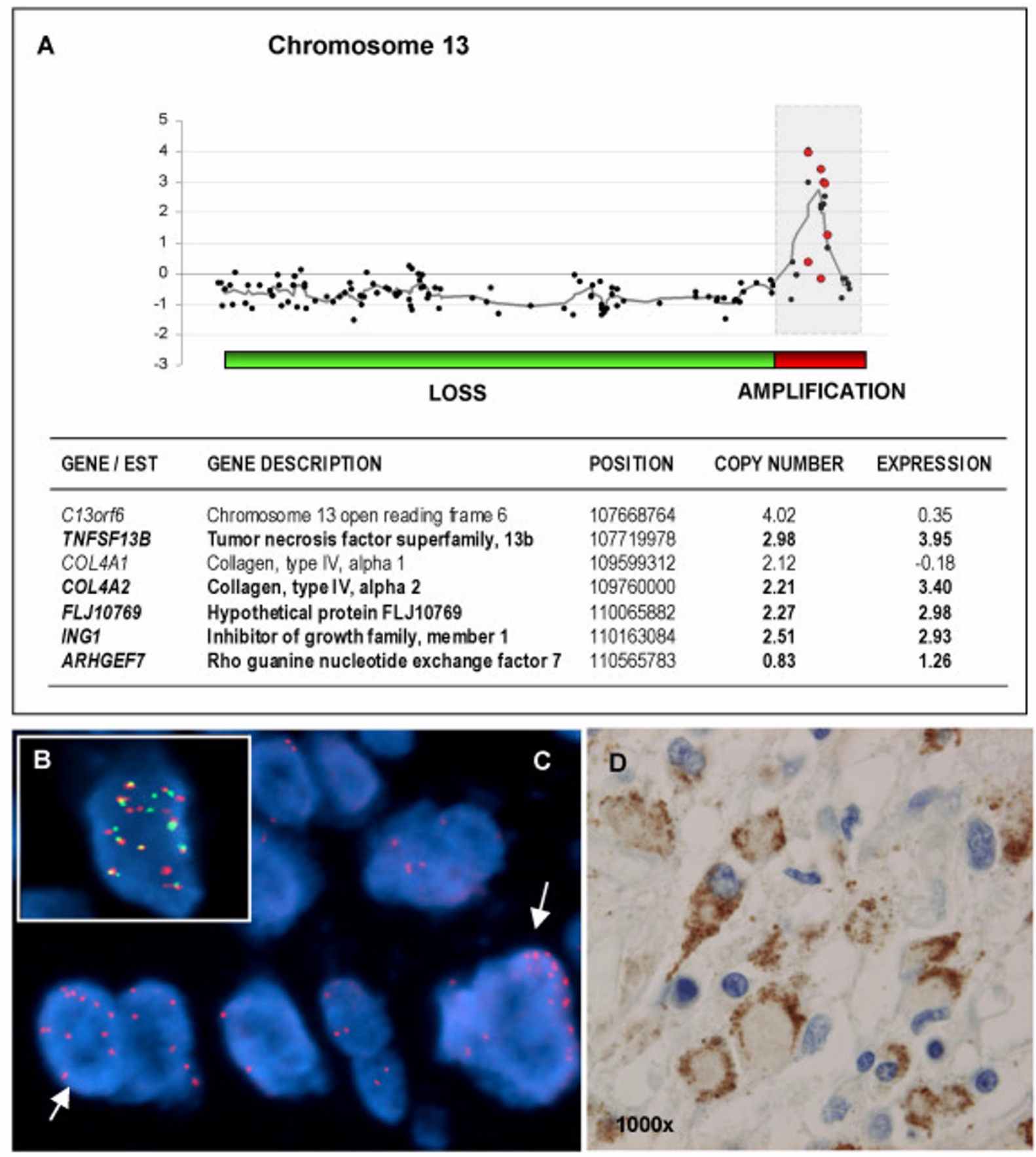

Figure 3

Amplification at I3q. (A) DNA copy number and expression log 2 ratios (black and red dots, respectively) of tumor 39b plotted according to the map position. Moving average of $\log _{2}$-genomic ratios over five neighboring genes are plotted and shown with a grey line. In the table below, amplified and overexpressed genes (in bold), with their corresponding log ${ }_{2}$-ratios, are detailed. Lost and amplified regions are indicated by green and red bars, respectively, under the graph. The amplified region at 13q32-34 is indicated by a grey square. (B) Amplification at I3q observed in one of the tumors of the TMA by using BAC probes located at I3q32.3 (labeled in red) and I3q33.2 (labeled in green). (C) Amplification on I3q32.3 in another GBM (BAC probes labeled in red). Amplified cells are indicated by arrows. (D) Photomicrograph of tumour tissue with positive expression for TNFSFI3B showing cytoplasmic pattern (original magnification $\times 1000$ ). 

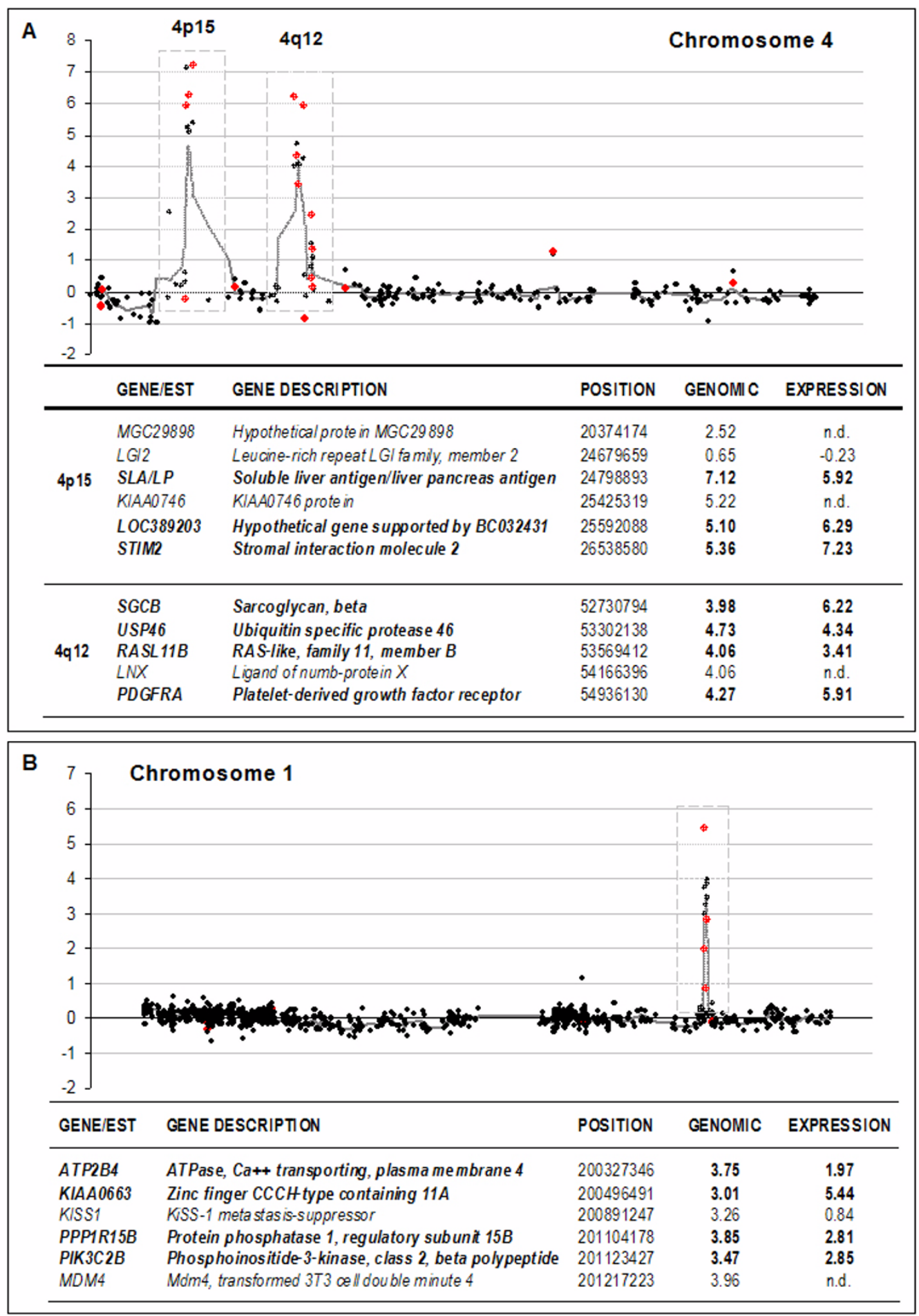

\section{Figure 4}

Amplification at chromosomes 4 and I. (A) DNA copy number ratios and expression $\log _{2}$ ratios (black and red dots, respectively) plotted with respect to their map position obtained for chromosome 4 of tumor $39 \mathrm{~b}$, and (B) for chromosome I of tumor $35 \mathrm{~b}$. Average $\log _{2}$ genomic values over five neighboring genes are shown with a grey line as a function of the location of the clones. Described in the corresponding tables below each graph are the amplified and overexpressed (in bold) genes together with their corresponding copy number and expression log2 values. 
Table 4: Amplicon at I 2q.

\begin{tabular}{|c|c|c|c|c|c|}
\hline & SYMBOL & GENE NAME & POSITION & $\begin{array}{l}\text { MEDIAN* } \\
\text { GENOMIC }\end{array}$ & $\begin{array}{c}\text { MEDIAN* } \\
\text { EXPRESSION }\end{array}$ \\
\hline \multirow[t]{7}{*}{ AMPLICON I } & SLC26A 10 & Solute carrier family 26, member 10 & 56290368 & 0.49 & 0.44 \\
\hline & GALGT & UDP-N-acetyl-alpha-D-galactosamine & 56305945 & 1.73 & 0.33 \\
\hline & SAS & Sarcoma amplified sequence & 56425051 & 0.49 & 2.92 \\
\hline & CDK4 & Cyclin-dependent kinase 4 & 56428272 & 2.44 & 4.12 \\
\hline & CYP27BI & Cytochrome P450, family 27, subfamily B, polypeptide I & 56442389 & 2.35 & 1.93 \\
\hline & TSFM & Ts translation elongation factor, mitochondrial & 56462849 & 1.02 & -0.26 \\
\hline & AVIL & Advillin & 56477704 & 1.84 & 0.53 \\
\hline \multirow[t]{4}{*}{ AMPLICON 2} & GNS & Glucosamine (N-acetyl)-6-sulfatase & 63393491 & 0.48 & 0.47 \\
\hline & CGI-II9 & CGI-I I9 protein & 64817459 & 0.94 & 5.38 \\
\hline & IFNG & Interferon, gamma & 66834816 & 0.76 & -0.02 \\
\hline & MDM2 & Mdm2, transformed $3 T 3$ cell double minute 2 & 67488247 & 2.72 & 1.64 \\
\hline
\end{tabular}

* Median of genomic or expression $\log _{2}$ ratios of gained genes.

Table 5: Amplicon at 7q.

\begin{tabular}{llccc}
\hline SYMBOL & GENE DESCRIPTION & POSITION & GENOMIC & EXPRESSION \\
\hline PFTKI & PFTAIRE protein kinase I & 89870462 & 1.68 & -0.58 \\
FZDI & Frizzled homolog I (Drosophila) & 90538434 & 3.05 & $\mathbf{2 . 9 1}$ \\
PEXI & Peroxisome biogenesis factor I & 9176099 I & 3.13 & 4.04 \\
CDK6 & Cyclin-dependent kinase 6 & 91878888 & 1.53 & 0.43 \\
\hline
\end{tabular}

Genomic and expression $\log _{2}$ ratios of gained genes.

the whole genome in GBM tumors and enables the refined and detailed study of amplicons and regions of recurrent copy number change. This approach makes it possible to identify putative glioma oncogenes/tumorsuppressor genes that may deserve further investigation. Our findings highlight the important influence in GBM of signaling pathways such as the PI3K/AKT, consistent with the invasive features of this tumor. In this context, we identify candidate target genes of amplification that may help to direct therapeutics for the treatment of GBM.

\section{Authors' contributions}

YR carried out selection of the GBM samples, performed nucleic acid extraction, DNA and RNA hybridizations onto the microarrays, FISH experiments, and participated in the discussion of the results. $\mathrm{MM}, \mathrm{TR}, \mathrm{CF}$, and FIC carried out histopathological analyses and pathological diagnosis. MM and FIC participated in the design of the study, and in the analysis and discussion of the results. EG participated in selection of the samples, DNA and RNA extraction, and carried out construction of the tissue arrays. AR-L and J-LH-M recovered clinical data of the patients and carried out clinical diagnostics. PM participated in the design and discussion of the results BM carried out statistical analysis of the microarray results, conceived of the study, drafted the manuscript, partici- pated in its design, and carried out coordination. All authors read and approved the final manuscript.

\section{Additional material}

\section{Additional file 1}

Genomic and expression row data. Genomic and expression row data of the GBM tumors. Gene symbol, gene description and localization are provided.

Click here for file

[http://www.biomedcentral.com/content/supplementary/14764598-5-39-S1.xls]

\section{Acknowledgements}

We would like to acknowledge the assistance of Lydia Sanchez (CNIO) with the immunohistochemical studies. Some of the BAC clones were generously provided by Dr. Mariano Rocchi (University of Bari, Italy).

This work was partially supported by grants from the Fondo de Investigaciones Sanitarias FIS 02/3006 and FIS 03/0727, and from the Consejería de Sanidad Junta de Comunidades de Castilla-La Mancha SESCAM GC30II and SESCAM 04032.

\section{References}

I. Gudinaviciene I, Pranys D, Juozaityte E: Impact of morphology and biology on the prognosis of patients with gliomas. Medicina (Kaunas) 2004, 40: I I2-1 20. 
2. Burton EC, Lamborn KR, Feuerstein BG, Prados $M$, Scott J, Forsyth $P$, Passe S, Jenkins RB, Aldape KD: Genetic aberrations defined by comparative genomic hybridization distinguish long-term from typical survivors of glioblastoma. Cancer Res 2002, 62:6205-6210

3. Inda MM, Fan X, Munoz J, Perot C, Fauvet D, Danglot G, Palacio A, Madero P, Zazpe I, Portillo E, Tunon T, Martinez-Penuela JM, Alfaro J, Eiras J, Bernheim A, Castresana JS: Chromosomal abnormalities in human glioblastomas gain in chromosome $7 \mathrm{p}$ correlating with loss in chromosome 10q. Mol Carcinog 2003, 36:6-14.

4. Hui AB, Lo KW, Yin XL, Poon WS, Ng HK: Detection of multiple gene amplifications in glioblastoma multiforme using arraybased comparative genomic hybridization. Lab Invest 200I, 81:717-723.

5. Pollack JR, Perou CM, Alizadeh AA, Eisen MB, Pergamenschikov A, Williams CF, Jeffrey SS, Botstein D, Brown PO: Genome-wide analysis of DNA copy-number changes using cDNA microarrays. Nat Genet 1999, 23:4|-46.

6. Beheshti B, Braude I, Marrano P, Thorner P, Zielenska M, Squire JA: Chromosomal localization of DNA amplifications in neuroblastoma tumors using cDNA microarray comparative genomic hybridization. Neoplasia 2003, 5:53-62.

7. Jiang F, Yin Z, Caraway NP, Li R, Katz RL: Genomic profiles in stage I primary non small cell lung cancer using comparative genomic hybridization analysis of cDNA microarrays. Neoplasia 2004, 6:623-635.

8. Mahlamaki EH, Kauraniemi P, Monni O, Wolf M, Hautaniemi S, Kallioniemi A: High-resolution genomic and expression profiling reveals 105 putative amplification target genes in pancreatic cancer. Neoplasia 2004, 6:432-439.

9. Pollack JR, Sorlie T, Perou CM, Rees CA, Jeffrey SS, Lonning PE, Tibshirani R, Botstein D, Borresen-Dale AL, Brown PO: Microarray analysis reveals a major direct role of DNA copy number alteration in the transcriptional program of human breast tumors. Proc Natl Acad Sci USA 2002, 99:12963-12968.

10. Wolf M, Mousses S, Hautaniemi S, Karhu R, Huusko P, Allinen M, Elkahloun A, Monni O, Chen Y, Kallioniemi A, Kallioniemi OP: Highresolution analysis of gene copy number alterations in human prostate cancer using CGH on CDNA micro arrays, impact of copy number on gene expression. Neoplasia 2004, 6:240-7.

II. Tracey L, Villuendas R, Ortiz P, Dopazo A, Spiteri I, Lombardia L, Rodriguez-Peralto JL, Fernandez-Herrera J, Hernandez A, Fraga J, Dominguez O, Herrero J, Alonso MA, Dopazo J, Piris MA: Identification of genes involved in resistance to interferon-alpha in cutaneous T-cell lymphoma. Am J Pathol 2002, 161:1825-1837.

12. Monni O, Barlund M, Mousses S, Kononen J, Sauter G, Heiskanen M, Paavola P, Avela K, Chen Y, Bittner ML, Kallioniemi A: Comprehensive copy number and gene expression profiling of the $17 \mathrm{q} 23$ amplicon in human breast cancer. Proc Natl Acad Sci USA 200I, 98:57II-57।6.

13. Vaquerizas JM, Dopazo J, Diaz-Uriarte R: DNMAD, web-based diagnosis and normalization for microarray data. Bioinformatics 2004, 20:3656-3658.

14. Herrero J, Diaz-Uriarte R, Dopazo J: Gene expression data preprocessing. Bioinformatics 2003, 19:655-656.

15. Palacios J, Honrado E, Osorio A, Cazorla A, Sarrio D, Barroso A, Rodríguez S, Cigudosa JC, Diez O, Alonso C, Lerma E, Sanchez L, Rivas C, Benitez J: Immunohistochemical characteristics defined by tissue microarray of hereditary breast cancer not attributable to BRCAI or BRCA2 mutations, differences from breast carcinomas arising in BRCAI and BRCA2 mutation carriers. Clin Cancer Res 2003, 9:3606-36I4.

16. The Ensembl database [http://www.ensembl.org]

17. The UCSC Genome Bioinformatics Site [http:// genome.ucsc.edu]

18. Schraml P, Kononen J, Bubendorf L, Moch $\mathrm{H}$, Bissig $\mathrm{H}$, Nocito A, Mihatsch MJ, Kallioniemi OP, Sauter G: Tissue microarrays for gene amplification surveys in many different tumor types. Clin Cancer Res 1999, 5:1966-1975.

19. Reifenberger G, Ichimura K, Reifenberger J, Elkahloun AG, Meltzer PS, Collins VP: Refined mapping of 12 q $13-q \mid 5$ amplicons in human malignant gliomas suggests CDK4/SAS and MDM2 as independent amplification targets. Cancer Res 1996, 56:5|4|-5|45
20. Pollack JR, Sorlie T, Perou CM, Rees CA, Jeffrey SS, Lonning PE, Tibshirani R, Botstein D, Borresen-Dale AL, Brown PO: Microarray analysis reveals a major direct role of DNA copy number alteration in the transcriptional program of human breast tumors. Proc Natl Acad Sci U S A 2002, 99: I2963-12968.

21. Hyman E, Kauraniemi P, Hautaniemi S, Wolf M, Mousses S, Rozenblum E, Ringner M, Sauter G, Monni O, Elkahloun A, Kallioniemi OP, Kallioniemi A: Impact of DNA amplification on gene expressionpatterns in breast cancer. Cancer Res 2002, 62:6240-6245.

22. Schwab M: Oncogene amplification in solid tumors. Semin Cancer Biol 1999, 9:319-325.

23. Galanis E, Buckner J, Kimmel D, Jenkins R, Alderete B, O'Fallon J, Wang $\mathrm{CH}$, Scheithauer BW, James CD: Gene amplification as a prognostic factor in primary and secondary high-grade malignant gliomas. Int J Oncol 1998, I3(4):717-724.

24. Olson JJ, Barnett D, Yang J, Assietti R, Cotsonis G, James CD: Gene amplification as a prognostic factor in primary brain tumors. Clin Cancer Res 1998, 4:215-222.

25. Mehra S, Messner H, Minden M, Chaganti RS: Molecular cytogenetic characterization of non-Hodgkin lymphoma cell lines. Genes Chromosomes Cancer 2002, 33:225-234.

26. Neat MJ, Foot N, Jenner M, Goff L, Ashcroft K, Burford D, Dunham A, Norton A, Lister TA, Fitzgibbon J: Localisation of a novel region of recurrent amplification in follicular lymphoma to an approximately $6.8 \mathrm{Mb}$ region of 13q32-33. Genes Chromosomes Cancer 200I, 32:236-243.

27. Rao PH, Houldsworth J, Dyomina K, Parsa NZ, Cigudosa JC, Louie DC, Popplewell L, Offit K, Jhanwar SC, Chaganti RS: Chromosomal and gene amplification in diffuse large B-cell lymphoma. Blood 1998, 92:234-240.

28. Ried T, Petersen I, Holtgreve-Grez H, Speicher MR, Schrock E, du Manoir S, Cremer T: Mapping of multiple DNA gains and losses in primary small cell lung carcinomas by comparative genomic hybridization. Cancer Res 1994, 54: I80I-I806.

29. Speicher MR, Howe C, Crotty P, du Manoir S, Costa J, Ward DC: Comparative genomic hybridization detects novel deletions and amplifications in head and neck squamous cell carcinomas. Cancer Res 1995, 55:1010-1013.

30. Nigro JM, Misra A, Zhang L, Smirnov I, Colman H, Griffin C, Ozburn N, Chen M, Pan E, Koul D, Yung WK, Feuerstein BG, Aldape KD: Integrated array-comparative genomic hybridization and expression array profiles identify clinically relevant molecular subtypes of glioblastoma. Cancer Res 2005, 65:1678-1686.

31. Ross DT, Scherf U, Eisen MB, Perou CM, Rees C, Spellman P, lyer V, Jeffrey SS, Van de Rijn M, Waltham M, Pergamenschikov A, Lee JC, Lashkari D, Shalon D, Myers TG, Weinstein JN, Botstein D, Brown $\mathrm{PO}$ : Systematic variation in gene expression patterns in human cancer cell lines. Nat Genet 2000, 24(3):227-235.

32. van den Boom J, Wolter M, Kuick R, Misek DE, Youkilis AS, Wechsler DS, Sommer C, Reifenberger G, Hanash SM: Characterization of gene expression profiles associated with glioma progression using oligonucleotide-based microarray analysis and realtime reverse transcription-polymerase chain reaction. $\mathrm{Am} J$ Pathol 2003, 163:1033-1043.

33. Tso CL, Freije WA, Day A, Chen Z, Merriman B, Perlina A, Lee Y, Dia EQ, Yoshimoto K, Mischel PS, Liau LM, Cloughesy TF, Nelson SF: Distinct transcription profiles of primary and secondary glioblastoma subgroups. Cancer Res 2006, 66:159-167.

34. Moreaux J, Legouffe E, Jourdan E, Quittet P, Reme T, Lugagne C, Moine P, Rossi JF, Klein B, Tarte K: BAFF and APRIL protect myeloma cells from apoptosis induced by interleukin 6 deprivation and dexamethasone. Blood 2004, 103:3 |48-3| 57.

35. Knobbe CB, Reifenberger G: Genetic alterations and aberrant expression of genes related to the phosphatidyl-inositol-3'kinase/protein kinase B (Akt) signal transduction pathway in glioblastomas. Brain Pathol 2003, I 3:507-5 18.

36. Weber RG, Sabel M, Reifenberger J, Sommer C, Oberstrass J, Reifenberger G, Kiessling M, Cremer T: Characterization of genomic alterations associated with glioma progression by comparative genomic hybridization. Oncogene 1996, 13(5):983-94.

37. Reifenberger G, Reifenberger J, Ichimura K, Collins VP: Amplification at $12 q 13-14$ in human malignant gliomas is frequently accompanied by loss of heterozygosity at loci proximal and distal to the amplification site. Cancer Res 1995, 55:73 I-734.

38. Williams RT, Manji SS, Parker NJ, Hancock MS, Van Stekelenburg L, Eid JP, Senior PV, Kazenwadel JS, Shandala T, Saint R, Smith PJ, Dzia- 
dek MA: Identification and characterization of the STIM (stromal interaction molecule) gene family, coding for a novel class of transmembrane proteins. Biochem J 200I, 357:673-685.

39. Knobbe $\mathrm{CB}$, Merlo $\mathrm{A}$, Reifenberger $\mathrm{G}$ : Pten signaling in gliomas. Neuro-oncol 2002, 4(3): 196-2II.

40. Riemenschneider MJ, Buschges R, Wolter M, Reifenberger J, Bostrom J, Kraus JA, Schlegel U, Reifenberger G: Amplification and overexpression of the MDM4 (MDMX) gene from Iq32 in a subset of malignant gliomas without TP53 mutation or MDM2 amplification. Cancer Res 1999, 59:6091-6096.

4I. Riemenschneider MJ, Knobbe CB, Reifenberger G: Refined mapping of Iq32 amplicons in malignant gliomas confirms MDM4 as the main amplification target. Int J Cancer 2003, 104:752-757.

42. Mariani L, Beaudry C, McDonough WS, Hoelzinger DB, Demuth T, Ross KR, Berens T, Coons SW, Watts G, Trent JM, Wei JS, Giese A, Berens ME: Glioma cell motility is associated with reduced transcription of proapoptotic and proliferation genes, a cDNA microarray analysis. J Neurooncol 200I, 53:161-176.

43. Huang $\mathrm{H}$, Colella $\mathrm{S}$, Kurrer M, Yonekawa $\mathrm{Y}$, Kleihues $\mathrm{P}$, Ohgaki $\mathrm{H}$ : Gene expression profiling of low-grade diffuse astrocytomas by cDNA arrays. Cancer Res 2000, 60:6868-6874.

44. Zhou Y, Bian X, Le Y, Gong W, Hu J, Zhang X, Wang L, Iribarren P, Salcedo R, Howard OMZ, Farrar W, Wang JM: Formylpeptide Receptor FPR and the Rapid Growth of Malignant Human Gliomas. J Natl Cancer Inst 2005, 97:823-835.

45. Gene Expression Pattern Analysis Suite [http://idcon verter.bioinfo.cipf.es]

Publish with Bio Med Central and every scientist can read your work free of charge

"BioMed Central will be the most significant development for disseminating the results of biomedical research in our lifetime. "

Sir Paul Nurse, Cancer Research UK

Your research papers will be:

- available free of charge to the entire biomedical community

- peer reviewed and published immediately upon acceptance

- cited in PubMed and archived on PubMed Central

- yours - you keep the copyright

Submit your manuscript here:

http://www.biomedcentral.com/info/publishing_adv.asp
BiolMedcentral 